\title{
Liver segment $2+3$ living donation in liver transplantation for colorectal liver metastases
}

\author{
Svein Dueland ${ }^{1}$, Pål-Dag Line ${ }^{2}$ \\ ${ }^{1}$ Department of Oncology, Oslo University Hospital, Oslo, Norway; ${ }^{2}$ Department of Transplantation Medicine, Oslo University Hospital, Oslo, \\ Norway and Institute of Clinical Medicine, University of Oslo, Norway \\ Correspondence to: Svein Dueland. Department of Oncology, Oslo University Hospital, Oslo, Norway. Email: svedue@ous-hf.no. \\ Provenance and Peer Review: This article was commissioned by the editorial office, Hepatobiliary Surgery and Nutrition. The article did not undergo \\ external peer review. \\ Comment on: Königsrainer A, Templin S, Capobianco I, et al. Paradigm Shift in the Management of Irresectable Colorectal Liver Metastases: Living \\ Donor Auxiliary Partial Orthotopic Liver Transplantation in Combination With Two-stage Hepatectomy (LD-RAPID). Ann Surg 2019;270:327-32.
}

Submitted Oct 24, 2019. Accepted for publication Nov 05, 2019.

doi: $10.21037 /$ hbsn.2019.11.15

View this article at: http://dx.doi.org/10.21037/hbsn.2019.11.15

Liver transplantation (LT) was offered to some colorectal cancer (CRC) patients with liver only metastases in the 1990s, however the treatment option was discontinued due to poor overall survival (OS) of $43 \%$ at 2 years posttransplant combined with the scarcity of donor organs at that time (1). In 2006 we initiated a pilot study reexamining LT in CRC patients. When the first patients had been observed for 5 years, the Kaplan-Meier estimated OS was $60 \%$ (2) and the survival outcome was much better compared to a similar cohort of CRC patients starting first line chemotherapy in the Nordic VII trial (3). LT is also a much better treatment option than any other medical treatment reported in CRC patients having progressive disease on standard chemotherapy including, oxaliplatin, irinotecan, EGDR-antibody and VEGF-antibody (bevacizumab) $(4,5)$.

The shortage of deceased donor livers in most countries generate long waiting times and elevated wait list mortality in many countries. Thus, LT for colorectal liver metastases might not be considered as a realistic possibility. On this background, we developed the RAPID technique, combining resection of liver segments $1-3$ and transplantation of an auxiliary segment $2+3$, followed by a delayed 2.stage final hepatectomy of the right liver remnant (6). An essential principle of the RAPID procedure is to protect the small liver graft from detrimental portal hyper-perfusion, whilst simultaneously ensuring that the graft gets optimal conditions for swift regeneration. After completion of the transplant, pressure and flow measurements are made continuously in the graft portal vein and hepatic artery. The portal flow is totally diverted to the graft by temporary clamping of the remnant right portal vein. If portal pressure in the graft is $\leq 15 \mathrm{mmHg}$ and arterial flow is maintained at $>75 \%$ of pre occlusion levels, the right portal branch is closed. Pressures above $15 \mathrm{mmHg}$ during the procedure will per protocol require inflow modulation. By this technique LT may be offered to more patients since one donor liver may extend the life of two patients, given that no pediatric recipient needs the $\mathrm{S} 2+3$ graft.

Köningsrainer et al. from Tübingen has taken the RAPID concept a step further by using living donation of S2+3 (7). They report a hospital stay of only six days and no complications for the donor with follow-up time of 22 months. Donation of the left lateral section of the liver is considered a low-risk procedure for the donor with a surgical risk profile similar to live kidney donation. The long term consequence of kidney donation is however different from liver segment $2+3$ donation since kidney donors have a small but elevated risk of chronic kidney failure as well as increased cardiovascular mortality late in life (8). In contrast donating part of a liver will result in regenerative growth of the liver remnant that restores total liver volume and function. Hence, the long-term consequences of left lateral liver segment donation are different from kidney donation.

The patient reported by Köningsrainer et al. had an ascending colon primary with multiple synchronous liver lesions. Time from diagnosis to LT was only about 
5 months. At time of LT the patient had stable disease on chemotherapy with a significant reduction in CEA levels. The patient had a relapse after about 5 months which was detected as elevated CEA and confirmed by liquid biopsy (7). At time of relapse the patient had bone and pulmonary metastases and palliative radiation therapy and chemotherapy were administered. Since no curative treatment was available in this situation and CRC patients with bone metastases in general have a dismal prognosis it is in our opinion unlikely that the patient transplanted by the Tübingen group would be a long-term survivor (more than 5 years from LT). We have now findings that indicate that patients with the primary tumor in the right colon have a significant worse OS after LT compared to patients with left-sided primary tumors. The patient also had synchronous disease and a short observation time from diagnosis to LT. These two factors are also negative with regards to post transplant survival according to our experience.

The authors did not follow the RAPID protocol entirely as described in the original publication, and second stage hepatectomy was performed in line with an ALPPS-like approach with 2. stage hepatectomy at post-transplant day 10 (7). The patient experienced a small-for-size like situation after the second stage with a clinical picture of graft dysfunction that was managed conservatively and resolved. It is in this context important to emphasize that the auxiliary graft should be protected from portal hyper-perfusion. Furthermore, when timing the 2.stage hepatectomy one should not only consider volume growth but also functional restoration. This implies that the safe interval between transplant and second stage most likely is between 2 and 3 weeks.

Our understanding and knowledge on prognostic factors for OS after LT is growing since we now have several patients included in our first LT study (SECA-I) that has survived for more than 10 years. Different scoring systems may be utilized to better predict the OS after LT. Utilizing the RAPID technique either from a deceased or a living donor may dramatically reduce the international problem with shortage of donor livers. Even when cure is not obtained LT may offer extended lifespan for many patients and this may be very important for the patients and their family members, thereby incentivizing family members towards donation. The obtainable prolongation of lifetime that is considered to be meaningful as a result of living donation and LT with the RAPID technique will probably differ among patients and their families.

Resource allocation and utilization is also a relevant aspect to consider in this discussion. It has been shown by our group that LT of colorectal liver metastases is a reasonable and cost effective treatment in high income countries when selecting "low risk" patients (9). Furthermore, we have also reported that the transplanted patients sustain good quality of life after LT except for the first 3 post-transplant months. Six months after transplantation the patients had recovered and their quality of life values were back to baseline values for global health score and physical function scores (10).

Living donation of segment $2+3$ may in the future be a treatment option for selected CRC patients expanding the possibility of offering LT to this group of patients. One should keep in mind that the procedure is technically demanding and most likely associated with a somewhat higher risk for complications for the recipients compared to standard LT procedure. Therefore, this type of surgery should only be performed in highly specialized transplant centers and preferably as part of prospective clinical trials.

\section{Acknowledgments}

Funding: None.

\section{Footnote}

Conflicts of Interest: Both authors have completed the ICMJE uniform disclosure form (available at http://dx.doi. org/10.21037/hbsn.2019.11.15). The authors have no conflicts of interest to declare.

Ethical Statement: The authors are accountable for all aspects of the work in ensuring that questions related to the accuracy or integrity of any part of the work are appropriately investigated and resolved.

Open Access Statement: This is an Open Access article distributed in accordance with the Creative Commons Attribution-NonCommercial-NoDerivs 4.0 International License (CC BY-NC-ND 4.0), which permits the noncommercial replication and distribution of the article with the strict proviso that no changes or edits are made and the original work is properly cited (including links to both the formal publication through the relevant DOI and the license). See: https://creativecommons.org/licenses/by-nc$\mathrm{nd} / 4.0 \%$. 


\section{References}

1. Muhlbacher F, Huk I, Steininger R, et al. Is orthotopic liver transplantation a feasible treatment for secondary cancer of the liver? Transplant Proc 1991;23:1567-8.

2. Hagness M, Foss A, Line PD, et al. Liver transplantation for nonresectable liver metastases from colorectal cancer. Ann Surg 2013;257:800-6.

3. Dueland S, Guren TK, Hagness M, et al. Chemotherapy or liver transplantation for nonresectable liver metastases from colorectal cancer? Ann Surg 2015;261:956-60.

4. Grothey A, Van Cutsem E, Sobrero A, et al. Regorafenib monotherapy for previously treated metastatic colorectal cancer (CORRECT): an international, multicentre, randomised, placebo-controlled, phase 3 trial. Lancet 2013;381:303-12.

5. Mayer RJ, Van Cutsem E, Falcone A, et al. Randomized trial of TAS-102 for refractory metastatic colorectal cancer. N Engl J Med 2015;372:1909-19.

Cite this article as: Dueland S, Line PD. Liver segment $2+3$ living donation in liver transplantation for colorectal liver metastases. HepatoBiliary Surg Nutr 2020;9(3):382-384. doi: 10.21037/hbsn.2019.11.15
6. Line PD, Hagness M, Berstad AE, et al. A Novel Concept for Partial Liver Transplantation in Nonresectable Colorectal Liver Metastases: The RAPID Concept. Ann Surg 2015;262:e5-9.

7. Köningsrainer A, Templin S, Capobianco I, et al. Paradigm Shift in the Management of Irresectable Colorectal Liver Metastases: Living Donor Auxiliary Partial Orthotopic Liver Transplantation in Combination With Two-stage Hepatectomy (LD-RAPID). Ann Surg 2019;270:327-32.

8. Mjoen G, Hallan S, Hartmann A, et al. Long-term risks for kidney donors. Kidney Int 2014;86:162-7.

9. Bjornelv GMW, Dueland S, Line PD, et al. Costeffectiveness of liver transplantation in patients with colorectal metastases confined to the liver. Br J Surg 2019;106:132-41.

10. Dueland S, Line PD, Hagness M, et al. Long-term quality of life after liver transplantation for non-resectable colorectal metastases confined to the liver. BJS Open 2018;3:180-5. 